\title{
CONSUMO DE UM SUPLEMENTO ALIMENTAR POR GESTANTES E NUTRIZES DE UMA UNIDADE DE SAÚDE DE RIBEIRÃO PRETO, SP (BRASIL)
}

Judith Costa *

Madalena Pereira Lima Taliberti

\begin{abstract}
COSTA, J, \& TALIBERTI, M.P.L. Consumo de um suplemento alimentar por gestantes e nutrizes de uma unidade de saúde de Ribeirão Preto, SP (Brasil). Rer. Saúde públ., S. Paulo, 15:472-7, 1981.

RESUMO: Descreve-se como as gestantes e nutrizes de uma Unidade Estadual de Saude que recebem o suplemento alimentar protéico "Gestal" o consomem, e se verifica se a quantidade ingerida é a recomendada pelo serviço.
\end{abstract}

UNITERMOS: Gestantes, estado nutricional, Suplemento alimentar. Inquérito nutricional, Ribeirão Preto, SP, Brasil.

\section{INTRODUÇ̃̃O}

Os serviços de saúde do Estado de São Paulo têm desenvolvido programa de distribuição de leite em pó como alimentação substituta ou complementar a mães de baixa renda com filhos de 0 a 1 ano e de baixo peso, na tentativa de diminuir a taxa de mortalidade infantil, direta ou indiretamente responsabilizada pela má nutrição nessa faixa etária.

A essa programação foi adicionado novo programa de distribuição de um alimento suplementar a gestantes nutrizes, que visa a: - melhorar as condições de nascimento e proporcionar maior peso do recém-nascido através de uma dieta mais balanceada da mãe durante a gestação;

- incentivar o aleitamento natural;

- prolongar o período de amamentação proporcionando às crianças mılhor estado nutritivo a fim de minimizar os riscos de infecções gastrointestinais a que estão expostas nos seus primeiros meses de vida.

O programa de distribuição do suplemento alimentar da Secretaria da Saúde do Estado de São Paulo, já em prática há alguns anos, vem sendo executado em todas as unidades de Saude do Estado.

As instruções gerais para o desenvolvimento do programa recomendam que toda nutriz ou gestante tem direito de receber o alimento suplementar e que sua indicação deve ser feita na primeira consulta médica . Há normas sobre o fornecimento do alimento especificando a quantidade a ser entregue, a orientação a ser dada e os requisitos necessários para que as pacientes recebam o suplemento, e sanções para as pacientes que falham no cumprimento do que é Exigido. As instruçōes existentes orientam para que a avaliação e o controle sejam feitos através da criança, isto é, da variação

* Do Departamento de Enfermagem Geral e Especializada - Disciplina de Enfermagem de Saúde Pública da Escola de Enfermagem de Riheirão Preto - USP - Campus Monte Alegre - 14100 - Ribeirão Preto, SP - Brasil. 
COSTA, J. \& TALIBERTI, M.P.L. Consumo de um suplemento alimentar por gestantes e nutrizes de uma unidade de saúde de Ribeirão Preto, SP (Brasil). Rev. Saúde públ., S. Paulo, 15:472-7, 1981.

do seu peso além dos registros de outros dados sobre seu desenvolvimento.

$\mathrm{Na}$ Unidade de Saude onde observamos o programa, as orientações sobre o preparo e importância do suplemento são dadas individualmente na pós-consulta, pelas visitadoras. $O$ fornecimento do suplemento é realizado por uma funcionária da farmácia que também entrega o leite das crianças e/ou medicamentos prescritos. Além do controle e avaliação expressos nas normas gerais da Unidade consideramos que havia necessidade de estudos sobre os mesmos para apurar resultados reais desses programas.

Massoni 2, em pesquisa sobre o "Gestal" no centro de Saúde de Jaú (SP) considera que o suplemento está tendo uma excelente aceitação entre as pacientes daquele serviço. Temos informações de que outros estudos estão sendo realizados para verificação do aproveitamento do novo suplemento.

Com a finalidade de obter subsidios para melhor desenvolvimento do programa na Unidade onde atuamos na região de Ribeirão Preto, quizemos verificar como as gestantes e nutrizes que estão recebendo o suplemento, o aceitam, quanto gostam, quais os sabores preferidos, maneira de prepará-lo $e$ se a quota que deve ser distribuida mensalmente está esendo consumida no prazo estipulado.

\section{MATEPIAL E METODOS}

De nome comercial "Gestal" 3 o suplemento é composto de $15 \%$ de leite, $5 \%$ de soja, $35 \%$ de açúcar e $25 \%$ de farinha de milho gelatinada. $O$ suplemento é apresentado en forma de farinha com 5 sabores diferentes, acondicionados em latas ou en embalagem de plástico, com peso líquido de $500 \mathrm{~g}$. O fornecimento é de 6 unidades para gestantes e 9 para inutrizes, quota para ser consumida em um mês em doses en torno de $150 \mathrm{~g}$. por dia em duas ou três rezes. A gestante poderá receber o suplemento du- rante toda a gestação e a nutriz durante o tempo que amamentar.

A população em estudo constou de 109 pacientes, sendo 54 gestantes e 55 nutrizes que freqüentam uma Unidade Sanitária de Ribeirão Preto, Estado de São Paulo, e que tinham iniciado o recebimento do suplemento pelo menos há um mês. Todas as pacientes eram residentes no bairro onde se localiza a Unidade Sanitária. A duração do estudo foi de 6 meses, iniciando-se em março de 1979 .

O levantamento dos dados foi realizado por meio de um questionário elaborado e preenchido em entrevista, no próprio Serviço, por ocasião do comparecimento das pacientes para receber o suplemento. As questões destinaram-se a obtenção de dados para caracterização do grupo como: idade, escolaridade, renda familiar, condições sanitárias e habitacionais, além de informações sobre preferência pelos sabores em que o suplemento é oferecido, seu preparo e seu consumo durante o mês.

Das 119 pacientes entrevistadas foi sorteada a metade para visitação no domicílio a fim de se obter dados sobre alimentação habitual e continuidade na ingestão do suplemento.

\section{RESULTADOS E DISCUSSÄO}

Os dados obtidos sobre idade, escolaridade, renda familiar, condições de alimentação, de habitação e sanitárias, nos permitiram constatar um grupo com características sócio-econômicas semelhantes, residentes no mesmo bairro, freqüentando a niesma Unidade Sanitária e cuja alimentação básica é arroz e feijāo.

Dentre os 5 sabores em que o suplemento $\dot{t}$ apresentado morango, côco, natural, baunilha e caramelo, os dois primeiros, 36,69\% e $28,44 \%$ respectivamente (Tabela 1 ), são os mais aceitos por gestantes ou nutrizes; uma paciente informou que gostava de todos os sabores, e duas de nenhum. Nāo existia armazenado na Unidade Sanitária suplemento de todos os sabores, mesmo não 
COSTA, J. \& TALIBERTI, M.P.L. Consumo de um suplemento alimentar por gestantes e nutrizes de uma unidade de saúde de Ribeirão Preto, SP (Brasil). Rev. Saúde públ., S. Paulo, 15:472-7, 1981.

\section{T A B E L A 1}

Suplemento alimentar distribuido a um grupo de gestantes e nutrizes de uma Unidade Sanitária de Ribeirão Preto, segundo os sabores preferidos.

\begin{tabular}{lcc}
\hline Sabor & N & $\%$ \\
\hline Morango & 40 & 36,69 \\
Côco & 31 & 28,44 \\
Natural & 14 & $\mathbf{1 2 , 8 4}$ \\
Baunilha & 11 & 10,09 \\
Caramelo & 10 & $\mathbf{9 , 1 7}$ \\
Todos & 1 & 0,91 \\
Nenhum & 2 & 1,83 \\
\hline Total & 109 & $\mathbf{1 0 0 , 0 0}$ \\
\hline
\end{tabular}

recebendo o do sabor preferido as pacientes diziam tomá-lo.

Nem todas as pacientes preparavam 0 suplemento segundo a orientação recebida ou as instruções impressas na embalagem. Das 109 pacientes, 31 , ou seja, $28,44 \%$ o preparavam com leite, $22(20,18 \%)$ com água ou leite e $56(56,37 \%)$ só com água (Tabela 2).
Não há inconveniência ou prejuizo se o suplemento for preparado diferentemente da maneira que lhes é indicada. A adição de leite só pode enriquecer mais o suplemento, embora não seja necessário. É, acreditamos, vantajoso desde que as pacientes possam fazê-lo. No entanto, como foi possivel observar a escolha ou a preferência pelo modo do preparo não estava levando a paciente ao consumo da quota integral, como era de se esperar. Quando procuramos relacionar a maneira de preparar o suplemento com o quanto é ele consumido, não há concordância entre os dois procedimentos, isto é, a probabilidade da paciente que o prepara com leite ingerir a quantidade de suplemento que lhe é fornecida é de apenas $22,6 \%$. Em qualquer das maneiras de prepará-lo, o número das pacientes que não consomem a quota integralmente é maior de que o número das que consumem. Do total das 109 pacientes somente $36(33,0 \%)$ estão ingerindo toda a quota que lhes é fornecida, quer gostando muito, regularmente ou não gostando, quer preparando-o com leite, com leite e/ou água ou só com água. (Tabela 2).

T A B E J A 2

Suplemento alimentar distribuido a um grupo de gestantes e nutrizes de uma Unidade Sanitária de Ribeirão Preto, SP, segundo a maneira de preparo.

\begin{tabular}{|c|c|c|c|c|}
\hline \multirow{2}{*}{ Consumo } & \multicolumn{3}{|c|}{ Preparo com } & \multirow{2}{*}{ Total } \\
\hline & Leite & Leite ou Água & Ãgua & \\
\hline De toda a quota & $\begin{array}{c}7 \\
(22,6 \%)\end{array}$ & $\begin{array}{c}6 \\
(27,3 \%)\end{array}$ & $\begin{array}{c}23 \\
(41,1 \%)\end{array}$ & $\begin{array}{c}36 \\
(33,0 \%)\end{array}$ \\
\hline Quota dividida com os filhos & $\begin{array}{c}8 \\
(25,8 \%)\end{array}$ & $\begin{array}{c}11 \\
(50,0 \%)\end{array}$ & $\begin{array}{c}14 \\
(25,0 \%)\end{array}$ & $\begin{array}{c}33 \\
(30,3 \%)\end{array}$ \\
\hline Não consomem toda a quota & $\begin{array}{c}16 \\
(51,6 \%)\end{array}$ & $\begin{array}{c}\mathbf{5} \\
(22,7 \%)\end{array}$ & $\begin{array}{c}19 \\
(33,9 \%)\end{array}$ & $\begin{array}{c}40 \\
(36,7 \%)\end{array}$ \\
\hline Total & $\begin{array}{c}31 \\
(28,44 \%)\end{array}$ & $\begin{array}{c}22 \\
(20,18 \%)\end{array}$ & $\begin{array}{c}56 \\
(51,37 \%)\end{array}$ & $\begin{array}{c}109 \\
(100,0 \%)\end{array}$ \\
\hline
\end{tabular}


COSTA, J. \& TALIBERTI, M.P.L. Consumo de um suplemento alimentar por gestantes e nutrizes de uma unidade de saúde de Ribeirăo Preto, SP (Brasil). Rev. Saúde públ., S. Paulo, 15:472-7, 1981.

Também não há helação coerente entre gostar e consumir.
A probabilidade de consumir toda a quota desde que gosta será dado por:

$$
\begin{aligned}
& \operatorname{Pr}\{\text { Consumir }+/ \text { gostar }+\}=\frac{28}{59} \times 100=47,4 \% \\
& \operatorname{Pr}\{\text { Consumir }+/ \text { gostar } \pm\}=\frac{5}{29} \times 100=17,2 \% \\
& \operatorname{Pr}\{\text { Consumir }+/ \text { gostar }-\}=\frac{3}{21} \times 100=14,3 \% \\
& \operatorname{Pr}\{\text { Consumir }-/ \text { gostar }+\}=\frac{9}{59} \times 100=15,2 \% \\
& \operatorname{Pr}\{\text { Consumir }-/ \text { gostar } \pm\}=\frac{18}{29} \times 100=62,1 \% \\
& \operatorname{Pr}\{\text { Consumir }-/ \text { gostar }-\}=\frac{13}{21} \times 100=61,9 \%
\end{aligned}
$$

\begin{tabular}{|c|c|c|c|c|}
\hline \multirow{2}{*}{ Consumo } & \multicolumn{3}{|c|}{ Grau de Gostar } & \multirow{2}{*}{ Total } \\
\hline & Muito + & Regular \pm & Não - & \\
\hline De toda a quota & $\begin{array}{c}28 \\
(47,5 \%)\end{array}$ & $\begin{array}{c}5 \\
(17,2 \%)\end{array}$ & $\begin{array}{c}3 \\
(14,3 \%)\end{array}$ & $\begin{array}{c}36 \\
(33,0 \%)\end{array}$ \\
\hline Quota dividida com os filhos & $\begin{array}{c}22 \\
(37,2 \%)\end{array}$ & $\begin{array}{c}6 \\
(20,6 \%)\end{array}$ & $\begin{array}{c}13 \\
(61,90 \%)\end{array}$ & $\begin{array}{c}33 \\
(30,3 \%)\end{array}$ \\
\hline Não consomem toda a quota & $\begin{array}{c}9 \\
(15,2 \%)\end{array}$ & $\begin{array}{c}18 \\
(62,1 \%)\end{array}$ & $\begin{array}{c}13 \\
(61,90 \%)\end{array}$ & $\begin{array}{c}40 \\
(36,7 \%)\end{array}$ \\
\hline Total & 59 & 29 & 21 & 109 \\
\hline
\end{tabular}

T A B E L A 3

Suplemento alimentar distribuido a $1 \mathrm{~m}$ grupo de gestantes e nutrizes de uma Unidade Sanitária de Ribeirāo Preto, SP, segundo gosto e consumo no período de um mês.

Em qualquer dos dois casos, quer gostando ou não, quer preparando da maneira que lhes convenha e porque há também em qualquer condição, os filhos que partilham do suplemento, fica evidente que as pacientes não o estão ingerindo como o esperado, isto é, na proporção ou na medida que lhes seria util nutricionalmente: quantidade, freqüência, continuidade, no período previsto.

Das 54 pacientes sorteadas para visitação 
COSTA, J. \& TALIBERTI, M.P.L. Consumo de um suplemento alimentar por gestantes e nutrizes de uma unidade de saúde de Ribeirão Preto, SP (Brasil). Rev. Saúde públ., S. Paulo, 15:472-7, 1981 .

posterior no domicilio foram encontradas apenas 33. Informaçōes erradas sobre o endereço e mobilidade constante dessas familias são os fatores de maior insucesso nas visitações domiciliares para qualquer finalidade, nos serviços de Saúde Pública.

O objetivo da visita foi verificar a continuidade da ingestão do suplemento, a quantidade tomada por dia e duração ou tempo que estavam tomando quer como gestantes ou como nutrizes, além de outras informaçōes não convencionadas.

Das 33 visitadas, vinte e três pacientes, praticamente $70 \%$, haviam deixado de tomar o alimento por motivos alegados como "enjoar", "engravidar", "engordar", "criança morreu", "leite secou", "foi suspenso pelo médico ou preferiu dar mamadeira" (Tabela 4).

\section{T A B E L A 4}

Motivos da interrupção do suplemento entre as 38 gestantes e nutrizes visitadas que freqüentavam uma Unidade Sanitária de Ribeirão Preto, SP.

\begin{tabular}{lc}
\hline Motivos & No \\
\hline Enjoou & 4 \\
Engravidou & 1 \\
Engordou & 2 \\
Leite secou & 7 \\
Médico suspendeu & 4 \\
Criança morre:1 & 4 \\
Prefere a mamadeira & 1 \\
\hline Total & 23 \\
\hline
\end{tabular}

O tempo de uso do suplemento entre as visitadas variou de 2 a 6 meses e a quantidade ingerida por vez variaram de duas a três colheres, duas a três vezes por dia. A maioria não havia recebido a medida de plástico que deveria ser dada às pacientes para controle da dose indicada.

Pôde-se verificar também que outras pessoas além dos filhos tomavam o suplemento ainda que esporadicamente. Algumas o usavam para "fazer bolo" e encontrou-se casos de mães que o cediam para o vizinho.

Uma paciente no período de nosso trabalho, 2 meses após ter recebido as latas de suplemento, devolveu-as, uma delas estava toda perfurada por faca. Ao the perguntarmos a razão de abri-la dessa maneira, informou-nos que não possuia outro instrumento para abri-la e que o fazendo daquele modo pôde sentir o "cheiro" da farinha que a desagradou. Não chegou a diluí-la e experimentá-la.

Há diversas discussõets e criticas a respeito dos programas de suplementação alimentar, afirmando que seus resultados têm sido pouco satisfatórios porque em geral não obedecem a um planejamento prévio e não realizam nenhuma avaliação. Parece-nos que a distribuição do leite ou qualquer outro suplemento em si, nas Unidades Sanitárias, é mais valorizada do que as orientações sobre o mesmo ${ }^{1}$. A divisão do alimento entre familiares é freqüente e é uma realidade difícil ou impossivel de ser controlada pois envolve fatores econômicos e emocionais. É muito difícil deixar de repartir com os filhos um alimento quando não há outro igual ou melhor para dar-lhes sabendo-os necessitados. Ainda se observa que um programa de orientação mais intensa com objetivos definidos e metodologia adequada ao grupo a que se destina, com um controle sério junto às familias, talvez alcance resultados mais efetivos.

É também necessário que se lembre que o êxito do combate à desnutrição não está afeto apenas aos programas de nutrição suplementar. Desnutrição é resultante de diversos fatores e se faz necessária a realização de trabalhos concomitantes, multi-setoriais, integrados, que se proponham à eliminação desses fatores determinantes. Não é um problema cujos programas isolados ou unilaterais possam vir a resolvê-lo ${ }^{1}$. Sua solução não cabe portanto apenas ao Setor de Saúde. Mas desde que este Setor tenha assumido a. realização de programas para melhoria das condições 
COSTA, J. \& TALIBERTI, M.P.L. Consumo de um suplemento alimentar por gestantes e nutrizes de uma unidade de saúde de Ribeirão Preto, SP (Brasil). Rev. Saúde públ., S. Paulo, 15:472-7, 1981.

nutricionais de certos grupos carentes, esses devem merecer planejamento, organização e execução cuidadosos, baseados em avaliações locais ou gerais precisas.

\section{CONCLUSOES}

Dos resultados obtidos deste estudo, concluimos que:

- A maneira de preparar o suplemento (Gestal) não altera a atitude quanto ao consumo da quota recebida pelas nutrizes e gestantes.

- A probabilidade de consumir o suplemento integralmente independe da maneira de gostar: muito, regularmente ou nada.
- Das 109 pacientes entrevistadas apenas $36(33,0 \%)$ ingerem integralmente a quota recebida no prazo estipulado.

- Trinta e três pacientes $(30,3 \%)$ dividem-no com os filhos.

- Quarenta pacientes $(36,7 \%)$ ultrapassam o periodo dentro do qual deveriam tomá-lo, resultando também na diminuição da ingestão da quantidade ideal preconizada.

- Resta dúvida sobre se o sabor preferido elevaria ou não o consumo do suplemento. O suplemento armazenado era de diversos sabores, não se podendo verificar esse dado.

COSTA, J. \& TALIBERTI, M.P.L. [Consumption of a feeding supplement by expectant and nursing mothers at a Health Service in Ribeirão Preto, SP (Brazil)]. Rev. Saúde públ., S. Paulo, 15:472-7, 1981.

ABSTRACT: The way in which expectant and nursing mothers take the protein supplement "Gestal" prescribed for them by a S. Paulo State Health Service is described. Whether the quantity taken is the same as that prescribed is also investigated.

UNITERMS: Pregnancy. Nutrition surveys, Ribeirão Preto, SP, Brazil. Food, fortified.

\section{REFERENCIAS BIBLIOGRAFICAS}

1. DISCUSIONES Tecnicas de la XXIII Reunion del Consejo Directivo de la OPS: situacion nutricional y alimentaria en los paises de America Latina y el Caribe. Bol. Ofic. sanit. panamer., 80:498-528, 1976.

2. MAsSoni, L.M. Pesquisa sobre o gestal. In: Congresso Brasileiro de Higiene, 19\%/ /Congresso Paulista de Saúde Pública,
19, São Paulo, 1977. Resumos dos trabalhos: temas livres. São Pa:lo, 1977. 4.14.

3. SECRETARIA DA SAÚDE DO ESTADO DE SÃo PAULO. Coordenadoria de Saúde. Suplementação alimentar: gestantes e nutrizes. São Paulo, 1976. [mimeogra: fado].

Recebido para publicação em 24/03/1981 Aprovado para publicasão em 21/07/1981 